\title{
AGGRESSIVE BEHAVIOUR AND REPRODUCTION IN THE MONGOLIAN GERBIL, MERIONES UNGUICULATUS, RELATIVE TO AGE AND SEXUAL EXPERIENCE AT PAIRING
}

\author{
M. L. NORRIS AND G. E. ADAMS \\ A.R.C. Unit of Reproductive Physiology and Biochemistry, \\ University of Cambridge
}

(Received 2nd March 1972, accepted 15th July 1972)

The Mongolian gerbil is normally a very tame and tractable animal. In certain situations, however, it may behave aggressively as, for example, when sexually mature animals are paired. Schwentker (1963) regarded the Mongolian gerbil as monogamous, observing that when old females lost their mate they did not usually accept another. Marston \& Chang (1965) reported that polygamous mating groups were less successful than monogamous pairs and that careful supervision of mating groups was essential. They also noted that it was not possible to carry out test matings owing to the female's aggressiveness towards a strange male. In accord with these observations, Barfield \& Beeman (1968), who made a study of the oestrous cycle, found it necessary to introduce each female to a specific male to avoid aggression during the non-receptive periods. The behaviour patterns that precede fighting in this species have been described by Nyby, Thiessen \& Wallace (1970).

Concerning sexual development, the testes descend at 30 to 45 days of age (Nakai, Nimura, Tamura, Shimizu \& Nishimura, 1960; Schwentker, 1963; Marston \& Chang, 1965) and active spermatogenesis and mating behaviour take place at 70 to 84 days (Marston \& Chang, 1965). In the female, the vagina opens at 40 to 76 days (Nakai et al., 1960) whilst sexual maturity occurs at 63 to 84 days (Marston \& Chang, 1965).

All animals came from our own closed colony, the origin and general management of which have been described recently (Norris \& Adams, 1972). At pairing, a male and female of the desired age and sexual experience were placed in a cage measuring 15 in. $\times 10$ in. $\times 7$ in. (Type RM 2, NKP Gages Ltd). Initially, either the male or female was transferred to the prospective partner's box, but after the importance of 'territory' was established, both partners were transferred to a clean, neutral box. The various types of animal used consisted of 60-day-old virgin males and females, multiparous females aged more than 100 days and males aged more than 100 days. After pairing, which generally took place before 10.00 hours, all animals were watched for $15 \mathrm{~min}$ and then intermittently throughout the day; subsequently, they were inspected daily.

The incidence of mortality relative to the system of pairing was examined in 397 pairs. Mortality was high, reaching 10 to $11 \%$, when either mature 
males were transferred to the quarters of multiparous female, or vice versa. In each system, more than $80 \%$ of the deaths occurred amongst the introduced animals. When both partners were transferred to a fresh box, mortality was much reduced, amounting to less than $2 \%$, with neither sex suffering disproportionately.

Table 1 shows the results of fifty-eight pairings, which are divided into four groups according to the age and previous history of the two partners. Deaths were confined to the first 5 days following pairing after which the incidence of fighting was negligible. Both from the point of view of fighting and mortality, the least satisfactory combination was a young male (60 days old) with multiparous females (Group 4) followed by the pairing of young males with young females (Group 3). The most satisfactory combination was young females paired with sexually mature males (Groups 1 and 2). Experienced males tended to be more aggressive (compare Groups 1 and 2), though in this case fighting did not lead to deaths.

The interval from pairing to parturition varied significantly in the four groups: comparison of Groups 1,2 and 3 shows that the age and previous experience of the male exerted a significant effect. The interval was shortest, 40 days, when mature, sexually experienced males were used; on the other hand, it was particularly long, exceeding 90 days, where 60 -day virgin males were used, irrespective of the age of the female. Body weights at pairing and after parturition can be found in Table 1. In Group 4, pairing took place after parturition, when the female is normally highly receptive. Vaginal smears were taken twice daily at 09.00 and 17.30 hours from five of the eleven females for 20 days to determine whether mating had taken place. No spermatozoa were observed and it is, therefore, concluded that mating did not occur at that time.

The influence of separation and system of re-pairing on the incidence of fighting and mortality v'ere examined in fifteen pairs of animals. Separation of a monogamous pair for periods of up to 15 days did not lead to fighting. When re-pairing took place after an interval of 30 days, fighting was common, affecting two thirds of the fifteen pairs tested, although no deaths were recorded. After separation for 5 days and 'random' re-pairing so that no female received her original mate, the proportion fighting - one third--was lower than in the previous trial, but two males died amongst the five pairs that fought.

The present observations confirm earlier reports that, at pairing, Mongolian gerbils often behave aggressively towards each other and permit for the first time an evaluation of some of the factors involved. For example, whereas the mortality rate was about $10 \%$ when either partner was transferred to the other's box, it was no more than $2 \%$ when pairing took place in a clean, neutral box. This finding illustrates the importance of territory-marking in the gerbil. Links between the ventral gland territory marking by olfactory stimulation and extreme aggression shown by resident animals, even females, towards intruders have been noted by Nyby et al. (1970). The position is apparently even more complicated by an interaction between age and sex. Whilst the pairing of sexually mature females with young males resulted in heavy mortality (four out of eleven) even under neutral conditions, no deaths were 


\begin{tabular}{|c|c|c|c|c|c|c|}
\hline \multirow{2}{*}{ 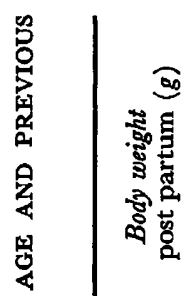 } & \multirow{2}{*}{ 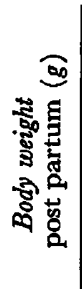 } & కี & 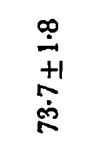 & 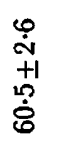 & $\begin{array}{l}\stackrel{+}{-1} \\
+1 \\
\stackrel{0}{0}\end{array}$ & $\begin{array}{l}\stackrel{P}{\dot{1}} \\
+1 \\
\stackrel{\leftrightarrow}{0}\end{array}$ \\
\hline & & ङूँ & $\begin{array}{l}+ \\
\dot{1} \\
+1 \\
\dot{0} \\
\dot{0}\end{array}$ & 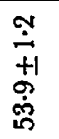 & $\begin{array}{l}\stackrel{9}{\dot{+}} \\
+1 \\
\stackrel{0}{0}\end{array}$ & $\begin{array}{l}\overrightarrow{\dot{v}} \\
+1 \\
\stackrel{\vec{F}}{\vec{n}}\end{array}$ \\
\hline 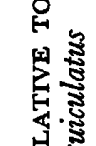 & 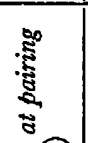 & ฐัँ & $\begin{array}{l}\stackrel{9}{+} \\
+1 \\
\stackrel{\infty}{\sim}\end{array}$ & $\begin{array}{l}\overrightarrow{\dot{\sim}} \\
+1 \\
\dot{n} \\
\dot{0}\end{array}$ & $\begin{array}{l}\stackrel{+}{\dot{H}} \\
\stackrel{+}{+} \\
\stackrel{\dot{P}}{+}\end{array}$ & $\begin{array}{l}\overrightarrow{\dot{m}} \\
\overrightarrow{+1} \\
\dot{\dot{q}}\end{array}$ \\
\hline 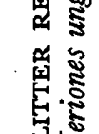 & 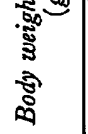 & 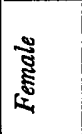 & 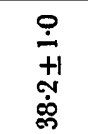 & $\begin{array}{l}\stackrel{\sim}{\dot{+}} \\
\stackrel{+}{\dot{m}}\end{array}$ & $\begin{array}{l}\stackrel{\sim}{\dot{+}} \\
\stackrel{+}{\sim} \\
\dot{\mathscr{j}}\end{array}$ & $\begin{array}{l}\stackrel{0}{\sim} \\
+1 \\
\dot{0}\end{array}$ \\
\hline 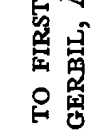 & 荵 & 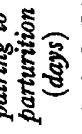 & $\begin{array}{l}m \\
+1 \\
+\end{array}$ & $\begin{array}{l}7 \\
+1 \\
0\end{array}$ & $\begin{array}{l}\infty \\
+1 \\
\infty\end{array}$ & $\begin{array}{l}\text { I } \\
\text { \%ั }\end{array}$ \\
\hline 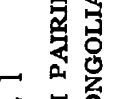 & $\dot{2}$ & & 2 & $\infty$ & $=$ & 0 \\
\hline 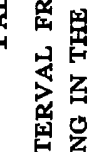 & $\begin{array}{l}5 \\
.5 \\
5 \\
5 \\
5 \\
5\end{array}$ & 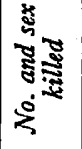 & 0 & 0 & 암 & to \\
\hline 思军 & క్ & 之. & + & 0 & n & N \\
\hline 覞 & s. & & 오 & $a$ & $\infty$ & $\Xi$ \\
\hline 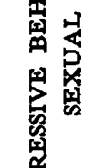 & ฟิํㅗㅀ & डัँ & 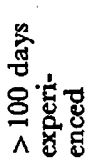 & 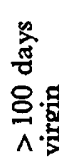 & 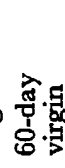 & 究.5 \\
\hline 器 & हू & छัँ & 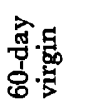 & 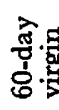 & 密.5 & 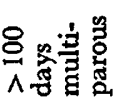 \\
\hline 崫 & हैँ & & - & N & $\infty$ & + \\
\hline
\end{tabular}


recorded in the reciprocal combination. None of our findings can be related to the stage of the oestrous cycle because, like Barfield \& Beeman (1968), we have experienced difficulty in characterizing it.

Significant differences in the interval from pairing to parturition were noted according to the age and previous sexual experience of the partners. Thus, the shortest mean interval of 40 days was recorded when 60 -day-old virgin females were paired with sexually experienced males aged over 100 days. Since gestation lasts 25 days, it is apparent that the majority of these females conceived at about 75 days of age, agreeing well with the 63 to 84 days given for sexual maturity by Marston \& Chang (1965). Similar females paired with young ( 60 days) and adult males ( $>100$ days) lacking sexual experience took, on average, 58 and 27 days longer, respectively, to conceive. The fact that most of the males ultimately sired litters proves that male sterility was not an important factor. Calculations based on Groups 2, 3 and 4 in Table 1 indicate that the males were approximately 130 to 140 days old when they sired their first litters, which seems late in relation to the 70 to 84 days reported by Marston \& Chang (1965) for the onset of spermatogenesis and mating behaviour.

The finding that monogamous pairs can be separated for periods of up to 15 days, and possibly even longer, without the risk of serious injury upon re-pairing is useful in certain experimental situations that demand separation. Nevertheless, limitations are still imposed, particularly if different males need to be introduced. However, by the use of the technique of paired emergence from anaesthesia, described recently by Cherkin \& Meinecke (1971) for the male rabbit, we have been able to pair satisfactorily animals that were previously aggressive (Norris \& Adams, 1972).

\section{REFERENGES}

Barfield, M. A. \& Beeman, E. A. (1968) The oestrous cycle in the Mongolian gerbil, Meriones unguiculatus. F. Reprod. Fert. 17, 247.

Cherkin, A. \& MEINECKE, R. O. (1971) Suppression of fighting behaviour in rabbits by paired emergence from anaesthesia. Nature, Lond. 231, 195.

Marston, J. H. \& Chang, M. C. (1965) The breeding, management and reproductive physiology of the Mongolian Gerbi (Meriones unguiculatus). Lab. Anim. Care, 15, 34.

Nakai, K., Nimura, H., Tamura, M., Shimizu, S. \& Nishimura, H. (1960) Reproduction and post natal development of the colony bred Meriones unguiculatus. Bull. exp. Anim., Tokyo, 9, 157.

Norris, M. L. \& ADAMs, G. E. (1972) The growth of the Mongolian gerbil, Meriones unguiculatus, from birth to maturity. F. Zool., Lond. 166, 277.

Norris, M. L. \& ADAMs, C. E. (1972) Suppression of aggressive behaviour in the Mongolian gerbil, Meriones unguiculatus. Lab. Anim. 6, 295.

Nyby, J., Thiessen, D. D. \& Wallace, P. (1970) Social inhibition of territorial marking in the Mongolian gerbil (Meriones unguiculatus). Psychonom. Sci. 21, 310.

SchwentKer, V. (1963) The gerbil. A new laboratory animal. Illinois Vet. 6, 5. 